\title{
THE HEART SOUNDS AND THE ARTERIAL PULSE IN CONGENITAL AORTIC STENOSIS
}

\author{
BY \\ JOHN REINHOLD, ULF RUDHE, AND R. E. BONHAM-CARTER \\ From the Hospital for Sick Children, Great Ormond Street; St. Mary's Hospital, London, and the \\ Karolinska Sjukhuset, Stockholm
}

Received February 10, 1955

Congenital valvular and subaortic stenosis are relatively rare lesions; Abbott (1936) found subaortic stenosis in 12, valvular stenosis in 11 and atresia in 12 in a series of 1000 autopsies of congenital heart disease, and Wood (1950) made this diagnosis in 2 per cent of his cases of congenital heart disease. Campbell and Kauntze (1953) believe that congenital aortic valvular stenosis is commoner than has previously been considered to be the case; they found it in 3 per cent of 460 cases of congenital heart disease. Of the first 1500 cases of congenital heart disease seen at the Hospital for Sick Children, we have made a diagnosis of aortic stenosis in about 6 per cent. Since the prognosis is bad in the most severe cases and since some of these may be amenable to operation, an exact diagnosis of this condition is important.

Whereas the nature of the systolic murmur and its phonocardiographic appearance are well recognized (Leatham, 1951), the nature of the heart sounds in aortic stenosis is not so clearly understood. There is considerable difference of opinion about the loudness of the second sound in the aortic area, and the nature of the first heart sound has not been clearly defined. This investigation is concerned with an analysis of the heart sounds in aortic stenosis by phonocardiography and a description of the typical arterial pulse.

\section{MATERIAL}

The investigation included fifteen patients with congenital aortic stenosis, 9 males and 6 females; twelve were children between the ages of 6 and 15 years and the remaining three were young adults. There was no doubt about the congenital nature of the lesion in every case, as the murmur had been first noted in infancy or early childhood. The diagnosis was made on the accepted clinical and radiographic criteria (Young, 1944; Grishman et al., 1947; Wood, 1950; Brown, 1950; Campbell and Kauntze, 1953). All patients had a systolic thrill and harsh loud systolic murmur in the aortic area transmitted up into the right side of the neck; in one there was also an aortic diastolic murmur. Differentiation between valvular and subaortic stenosis was not found to be possible on clinical, radiographic or electrocardiographic grounds. The phonocardiograms of twenty-five normal children have also been studied to estimate the normal degree of splitting of the second heart sound in the pulmonary area.

\section{METHODS}

Phonocardiograms, with three different frequency responses, were recorded from each patient. Those designated high frequency in the illustrative tracings are approximately the same as the logarithmic phonocardiogram of Rappaport and Sprague (1942) in their frequency response. The medium- and low-frequency tracings represent rather lower frequencies than are ordinarily heard through a stethoscope. Recordings were taken from the apex, fourth and second left intercostal 
spaces and second right intercostal space on a six-channel Elmqvist "Klinik" recorder. As reference tracings, lead II electrocardiograms and carotid artery tracings were recorded. The arterial tracings were obtained with a metal stylus resting on the suprasternal notch overlying the artery, impulses being transmitted directly to a crystal of Rochelle salt and the voltage so produced being amplified and subsequently recorded by a mirror galvanometer. There was no time lag in this circuit. This was estimated by bursting a balloon with a hot needle at a point equidistant from the metal stylus and a microphone; the deflection on the pressure tracing caused by the impact of the explosion was exactly synchronous with the initial vibration produced by the sound on a phonocardiogram. Allowance had to be made, however, for delay in pulse wave transmission from the aortic valve to the point where the recording was taken from the carotid artery. Assuming this to be an average distance of $10 \mathrm{~cm}$. and allowing a pulse wave velocity in the ascending aorta of $3 \mathrm{metres} / \mathrm{sec}$. (Bazett et al., 1935), this delay would be about $0.03 \mathrm{sec}$. in a child. One of us (U.R.) has confirmed this finding of a delay of pulse wave transmission in the ascending aorta of about $0.03 \mathrm{sec}$. in normal subjects, by comparing electrokymograms taken at the same heart rate from the base of the ascending aorta and from the aortic arch. We have also made this comparison in three of the patients with congenital aortic stenosis (Fig. 1). The point of upstroke of the aortic arch tracing followed that of the tracing from the base of the ascending aorta by $0.03,0.04$, and $0.06 \mathrm{sec}$. respectively. We have thus allowed $0.03 \mathrm{sec}$. delay in all tracings when calculating the timing of the upstroke on the carotid arterial pulse that denotes the onset of systolic ejection into the aorta.

In four patients, timing of the components of the heart sounds against mechanical events in the cardiac cycle was made by recording synchronous border electrokymograms with the phonocardiograms. The electrokymograms were taken from the base of the ascending aorta and pulmonary artery and from the left and right auricular appendages. The electrical delay in this circuit compared with the phonocardiogram was $0.01 \mathrm{sec}$. This was estimated by feeding an electric signal to the inputs of the electrocardiogram, phonocardiogram, and electrokymogram amplifiers. The response of each was recorded simultaneously and showed no time lag between the electrocardiogram and the phonocardiogram, and $0.01 \mathrm{sec}$. lag of the electrokymogram behind these two tracings. Consequently, an allowance of $0.01 \mathrm{sec}$. has been made in all tracings for this delay.

\section{RESULTS}

The First Heart Sound. Auscultation revealed what appeared to be accentuation of the first sound in all these patients, this accentuation being most easily heard at the apex. In several patients, the sound appeared to be widely split with the accentuation involving the second component of this splitting.

Phonocardiography revealed, in all but one patient, two distinct components at the apex following soon after the $\mathrm{Q}$ wave on the electrocardiogram (Fig. 2). These components were separated by an average of $0.05 \mathrm{sec}$. The first component followed the $\mathrm{Q}$ wave by an average of $0.05 \mathrm{sec}$., was best recorded at the apex

TABLE I

Relationship of Sounds Immediately following the Q Wave to eVents in the Cardiac CyCle in Congenital Aortic Stenosis

\begin{tabular}{|c|c|c|c|}
\hline Interval & $\begin{array}{c}\text { Average } \\
\text { duration (secs.) }\end{array}$ & Range & $\begin{array}{l}\text { No. of } \\
\text { patients }\end{array}$ \\
\hline $\begin{array}{l}\text { Separation of two components } \\
\text { Q-First component .. } \\
\text { Q-Estimated aortic valve opening } \\
\text { (calculated from carotid and aortic elec- } \\
\text { trokymogram tracings) } \\
\text { Q-Second component } \\
\text { Aortic valve opening-second component... }\end{array}$ & $\begin{array}{l}0.05 \\
0.05 \\
0.08 \\
0.10 \\
0.02\end{array}$ & $\begin{array}{c}0.04-0.09 \\
0.02-0.07 \\
0.06-0.14 \\
\\
0.06-0.16 \\
0.01-0.05 \\
\text { (Synchronous } \\
\text { in } 2 \text { cases) }\end{array}$ & $\begin{array}{l}14 \\
14 \\
14\end{array}$ \\
\hline
\end{tabular}




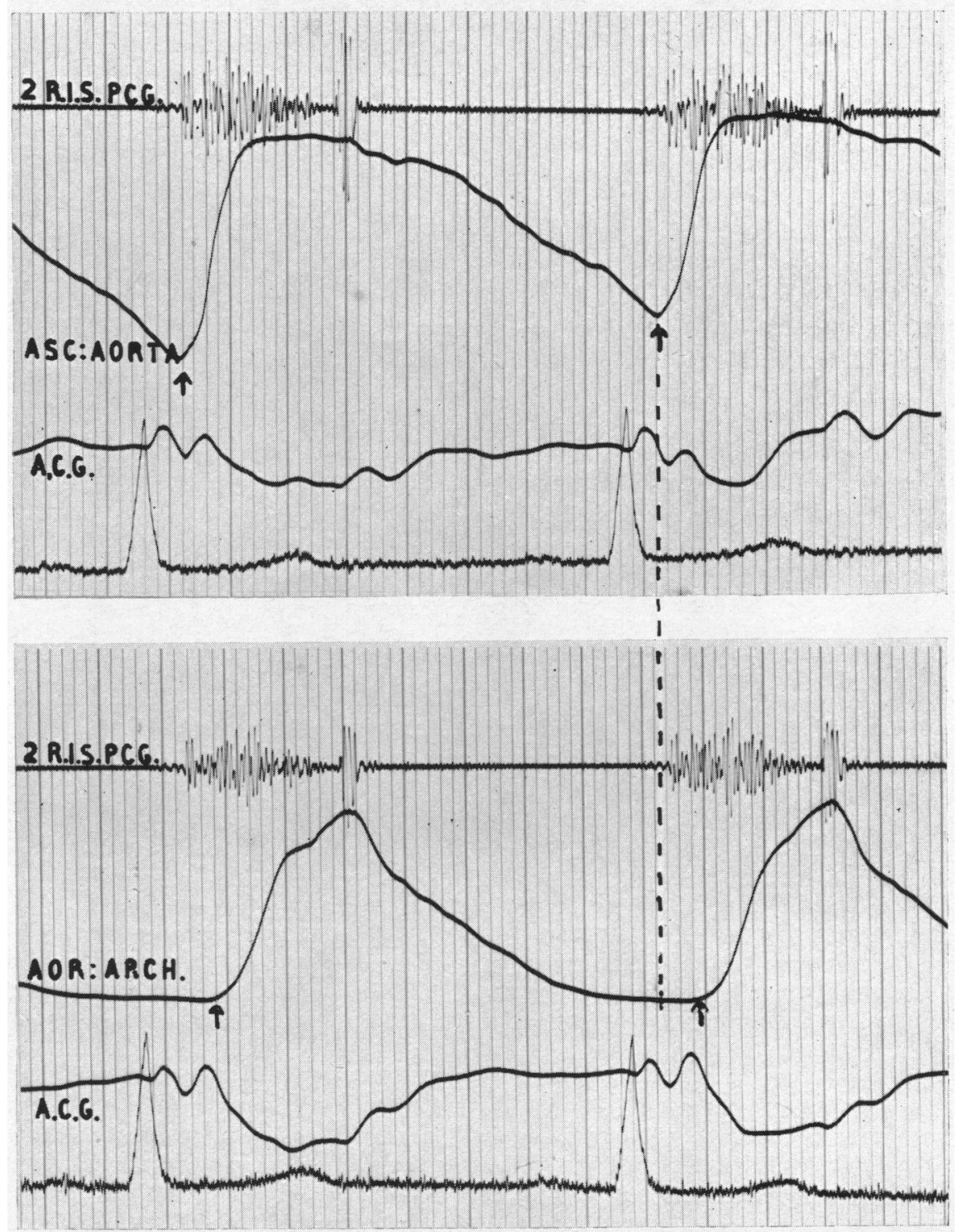

FiG. 1.-Border electrokymograms from the base of the ascending aorta and from the aortic arch, illustrating the delay due to pulse wave transmission in the ascending aorta in a case of congenital aortic stenosis. 2 R.I.S. PCG $=$ Phonocardiogram from the second right intercostal space. A.C.G. = Apex cardiogram. Time intervals in this and all subsequent records are 0.1 and 0.02 sec.

in all instances and was of rather high amplitude in 6 patients. It preceded the calculated time of onset of systolic ejection into the aorta by an average of $0.03 \mathrm{sec}$.

The second component followed the $Q$ wave by an average of $0.10 \mathrm{sec}$., and was of maximum amplitude at the apex in all cases. In the majority of patients it was also registered at the second right intercostal space, but with less amplitude (Fig. 3). It was of high amplitude in fourteen out of the fifteen cases, being consistently of much higher amplitude than the first component. It was invariably of rather high frequency (150-200 cycles per sec.) and in all instances, it occurred immediately before the onset of the systolic murmur. 


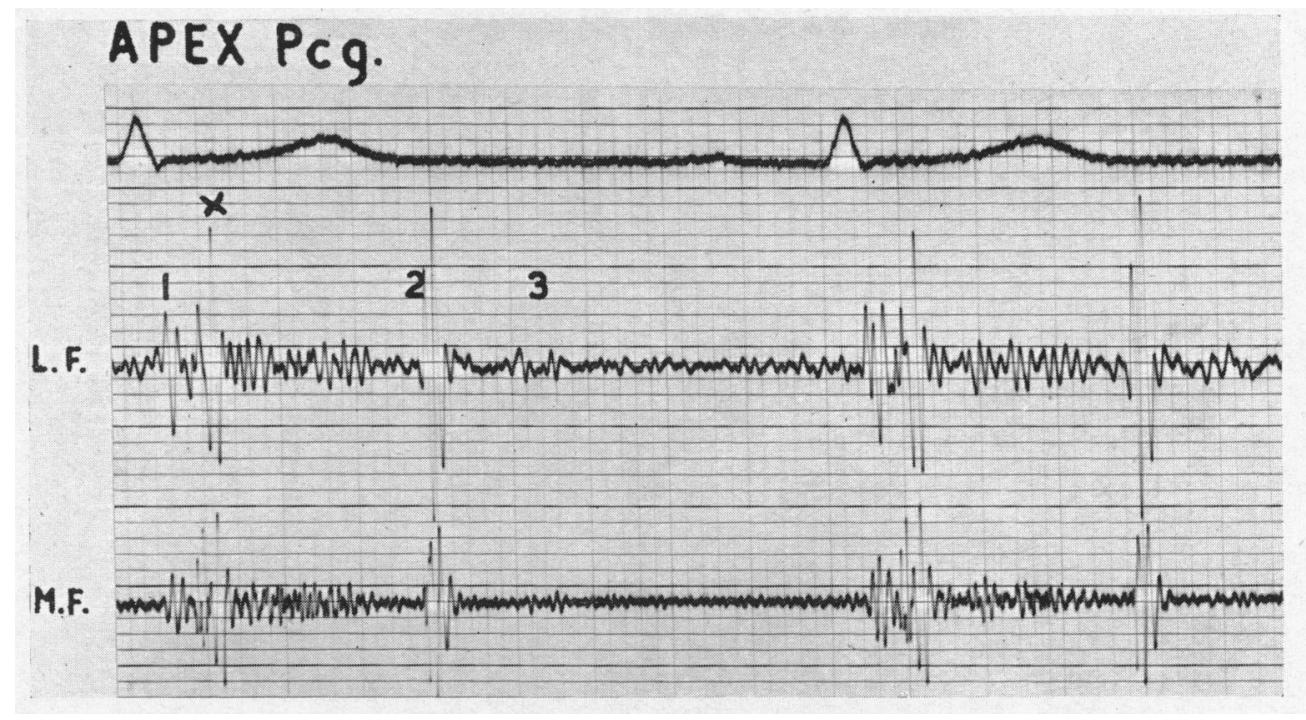

FIG. 2.-Apex phonocardiogram from a patient with congenital aortic stenosis, showing the separation of the two sounds immediately following the $Q$ wave. $X=$ Aortic systolic ejection sound. L.F. = Low frequency. M.F. = Medium frequency. $1=$ First heart sound. 2 = Second heart sound. $3=$ Third heart sound.

In 9 patients it was related to the time of opening of the aortic valves as calculated from the carotid tracing, and it was found to occur after the estimated time of aortic valve opening and the onset of systolic ejection into the aorta in all but one, the average delay being $0.02 \mathrm{sec}$. (Fig. 4). Therefore, it cannot be regarded as being part of the normal major components of the first heart sound as defined by Dock (1933) and Leatham (1954).

Timing of First Sound and early Systolic Components by Electrokymography. From its relationship to the $\mathrm{Q}$ wave on the electrocardiogram and to the upstroke of the carotid pulse, it seemed probable that the first component of the first sound was due to auriculo-ventricular valve closure. From the fact that it was best registered at the apex, mitral valve closure seemed to be the likely origin of this sound (Leatham, 1954). The relationship of the second component to the $\mathbf{Q}$ wave, its maximum intensity at the apex and its relation to the calculated time of onset of left ventricular systolic ejection made it seem probable that it was an early aortic systolic ejection sound.

Electrokymograms synchronous with the phonocardiograms were taken in four of these patients in an attempt to time these events more accurately. Luisada et al. (1948) have shown that the beginning of the upstroke following the nadir of the auricular systolic wave on the left auricular electrokymogram (Fig. 5) denotes the onset of isometric ventricular contraction and closure of the mitral valve. In two patients where the comparison was made, this point coincided with the onset of the first component on the phonocardiogram following the $\mathbf{Q}$ wave. It seems probable, therefore, that this sound is due to mitral valve closure.

In four patients, the point of onset of systolic ejection into the aorta was measured by an electrokymogram taken low down from the base of the ascending aorta (Fig. 5). As this tracing was calculated to have been taken from immediately above the aortic valves, no allowance had to be made for delay in pulse wave transmission. The initial vibrations of the second component were found to occur $0.02,0.03$, and $0.03 \mathrm{sec}$. after the onset of aortic systolic ejection in three patients; and the two events were synchronous in the fourth patient.

The Second Sound. By auscultation the second sound appeared to be normal or accentuated at the second right intercostal space or at the apex in all but one of these patients. At the second left intercostal space definite splitting of the second sound was only detectable in two patients. Phonocardiographic confirmation of these impressions was difficult as there was no calibration, but an attempt at estimating the 


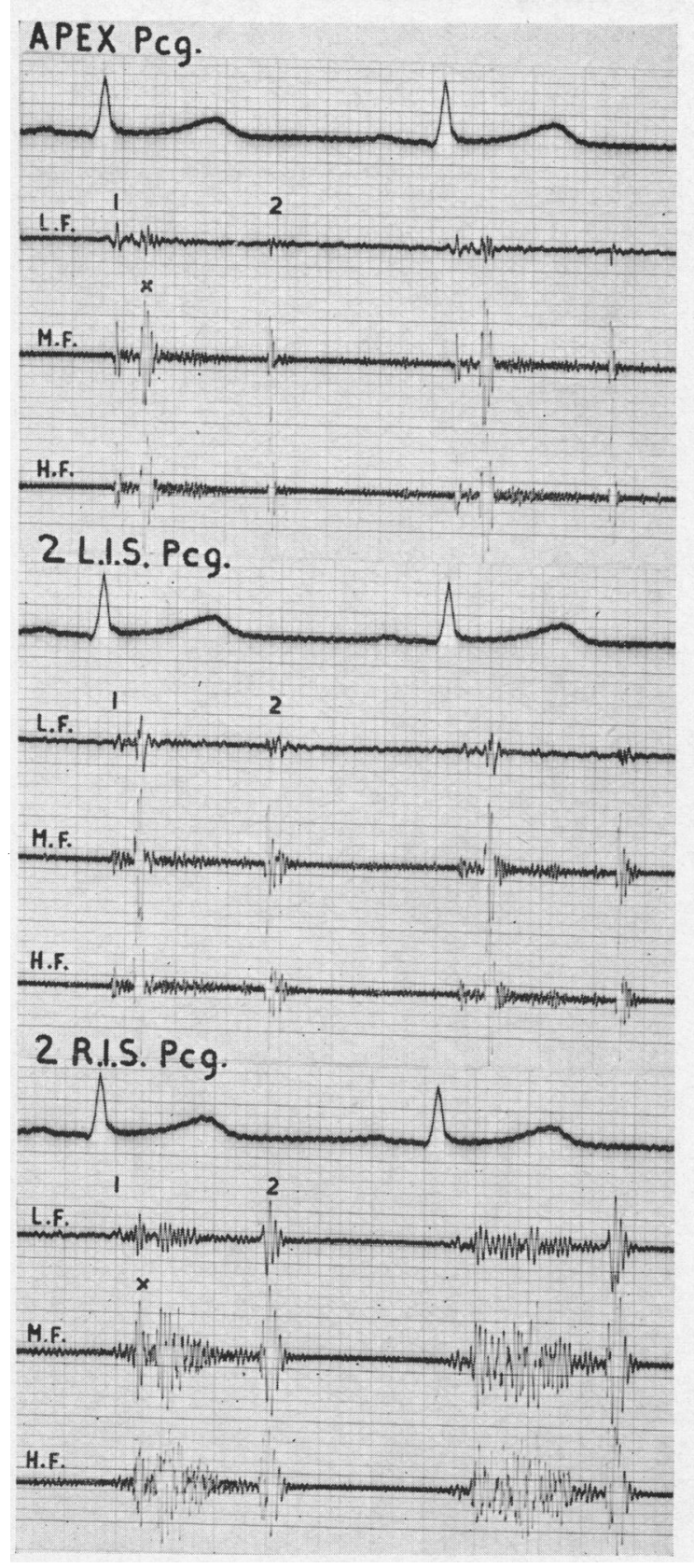

Fig. 3.-Phonocardiograms from the apex, second left intercostal space ( 2 L.I.S.), and second right intercostal space ( 2 R.I.S.) in a case of congenital aortic stenosis. The aortic systolic ejection sound ( $\mathrm{x}$ ) is well registered in all areas; it is uncommon for it to be so well recorded at the second left intercostal space. The rhomboid murmur at the second right intercostal space, ending before the second sound, is well shown in this recording. H.F. = High frequency.

amplitude of the aortic second sound was made by comparing the height of its components against that of the other sounds in the same complex. By this means, the aortic component of the second sound appeared to be normal in six patients and accentuated (Fig. 6) in eight patients. It was diminished in amplitude in one patient, who was not the one with associated aortic incompetence. It was best registered at the second right intercostal space in eight patients and at the apex in the remainder.

At the second left intercostal space, in fourteen patients, the aortic and pulmonary components were 
separate in nine and fused in five instances. The average interval between the onset of the two components was $0.02 \mathrm{sec}$. The average interval between the onset of these two components in twenty-five normal children was $\mathbf{0 . 0 4} \mathrm{sec}$. All these figures refer to tracings taken in mid-respiration.

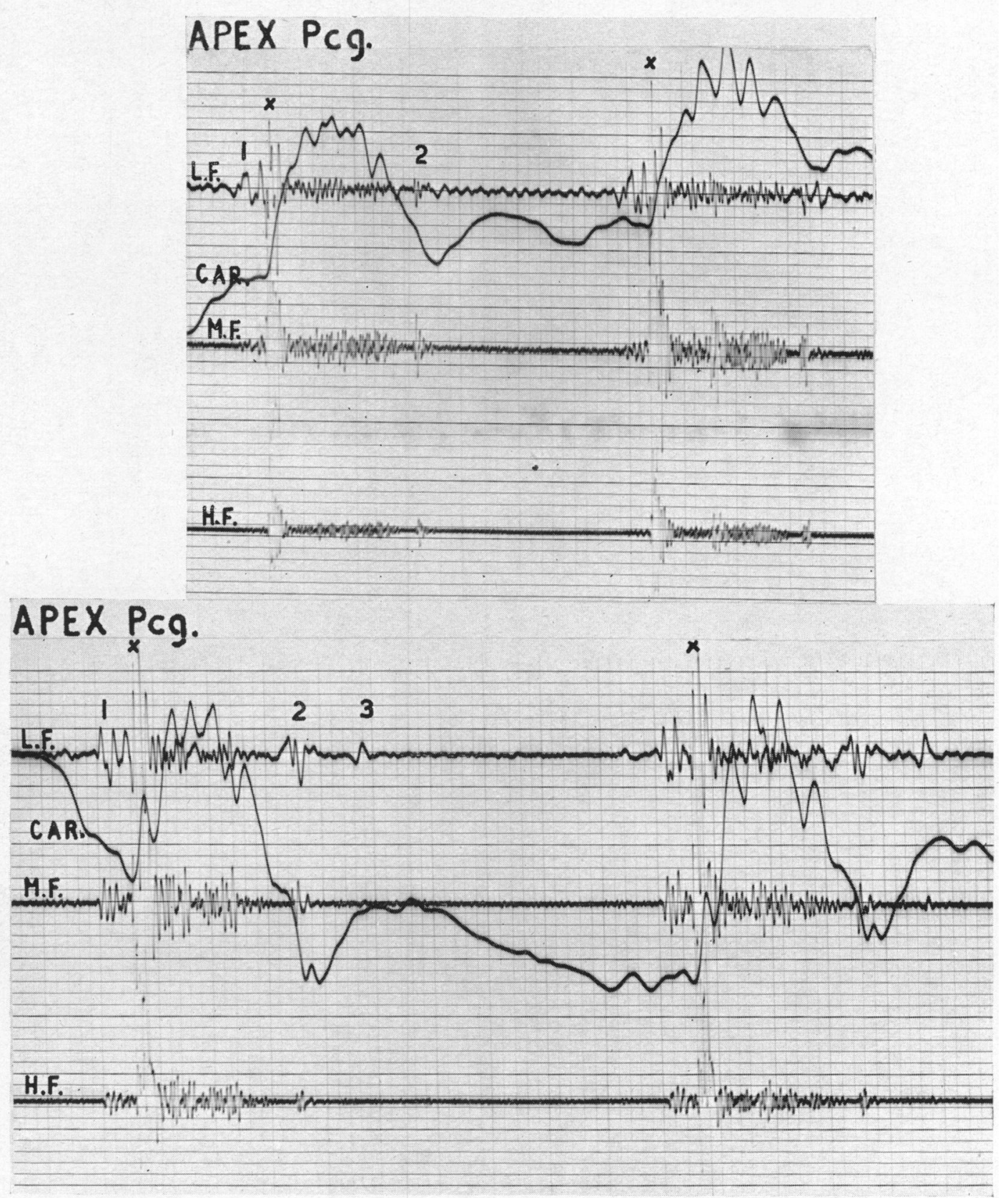

FIG 4.-Apex phonocardiograms from two patients with congenital aortic stenosis to show the relationship of the aortic systolic ejection sound (x) to the onset of systolic ejection into the aorta, calculated from the carotid (Car.) pulse. The delay due to pulse wave transmission from the aortic valves to the suprasternal notch is $0.03 \mathrm{sec}$. 


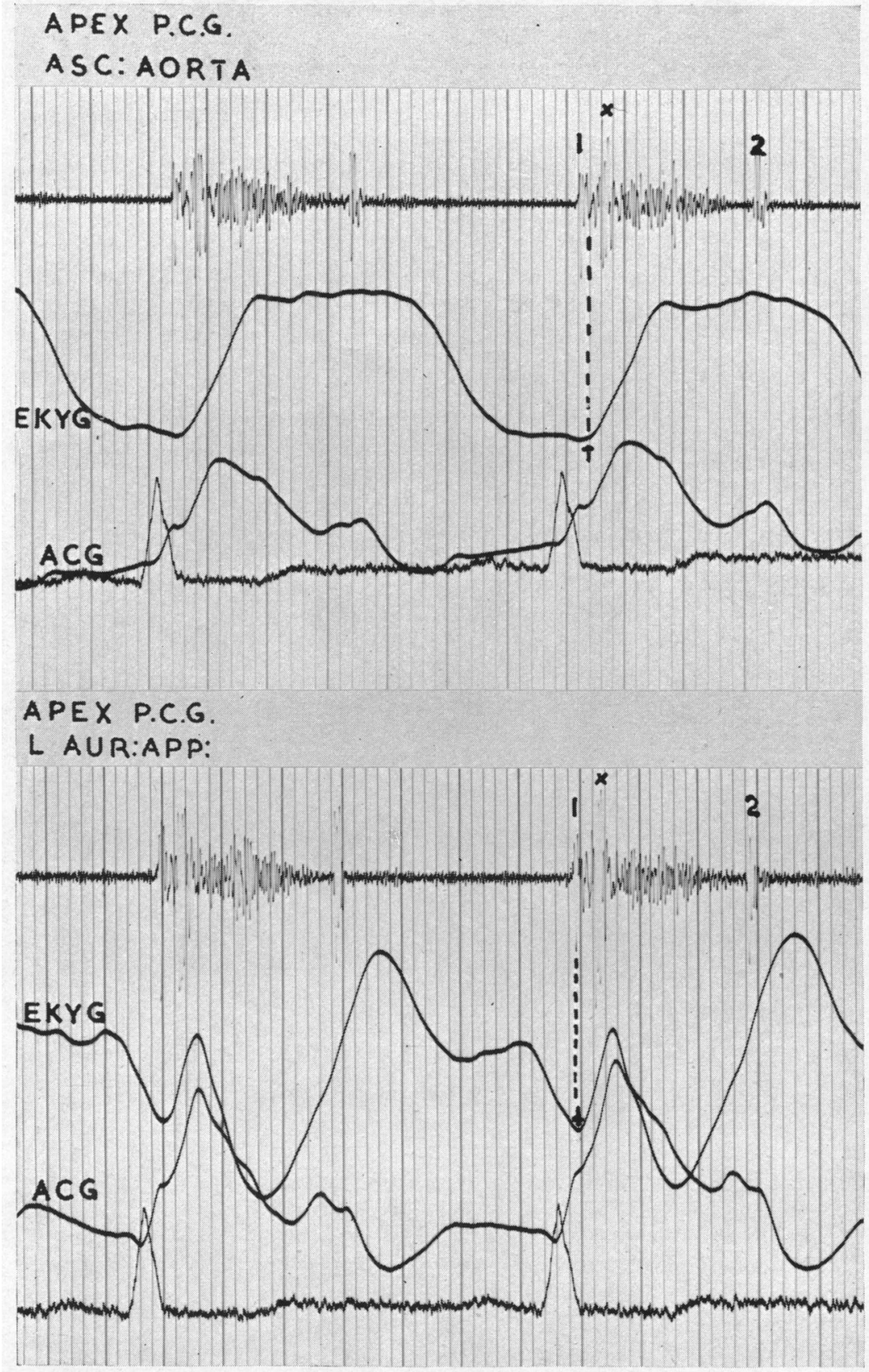

FIG. 5.-Synchronous apex phonocardiograms, apex cardiograms, electrocardiograms, and border electrokymograms from a patient with congenital aortic stenosis. The upper recording shows that the major vibrations of the first sound (1) precede the onset of systolic ejection into the aorta, indicated by the upstroke $(\uparrow)$ on the electrokymogram (Ekyg.) taken from the base of the ascending aorta. The second group of high-frequency vibrations (x) occurs $0.03 \mathrm{sec}$. after the onset of aortic systolic ejection.

In the lower recording, the onset of isometric ventricular contraction and closure of the mitral valve $(\downarrow)$ on the left auricular appendage electrokymogram (Ekyg.) is exactly synchronous with the first sound. 
TABLE II

The Second Sound in 15 Cases of Congenital Aortic Stenosis

\begin{tabular}{c|c|c|c|c|c|c|c|c}
\hline \multicolumn{2}{c|}{ Amplitude } & \multicolumn{2}{c|}{ Max. Registration } & \multicolumn{2}{c|}{ Splitting at 2 LIS. } & \multicolumn{2}{c}{$\begin{array}{c}\text { Splitting at 2 LIS. } \\
\text { in 25 normal children }\end{array}$} \\
\cline { 1 - 6 } Normal & $\begin{array}{c}\text { Accentu- } \\
\text { ated }\end{array}$ & Diminished & Apex & 2 RIS. & $(\mathrm{sec})$. & Range & (sec.) & Range \\
\hline 6 & 8 & 1 & 7 & 8 & 0.02 & $(0.02-0.03)$ & 0.04 & $(0.03-0.05)$ \\
\hline
\end{tabular}

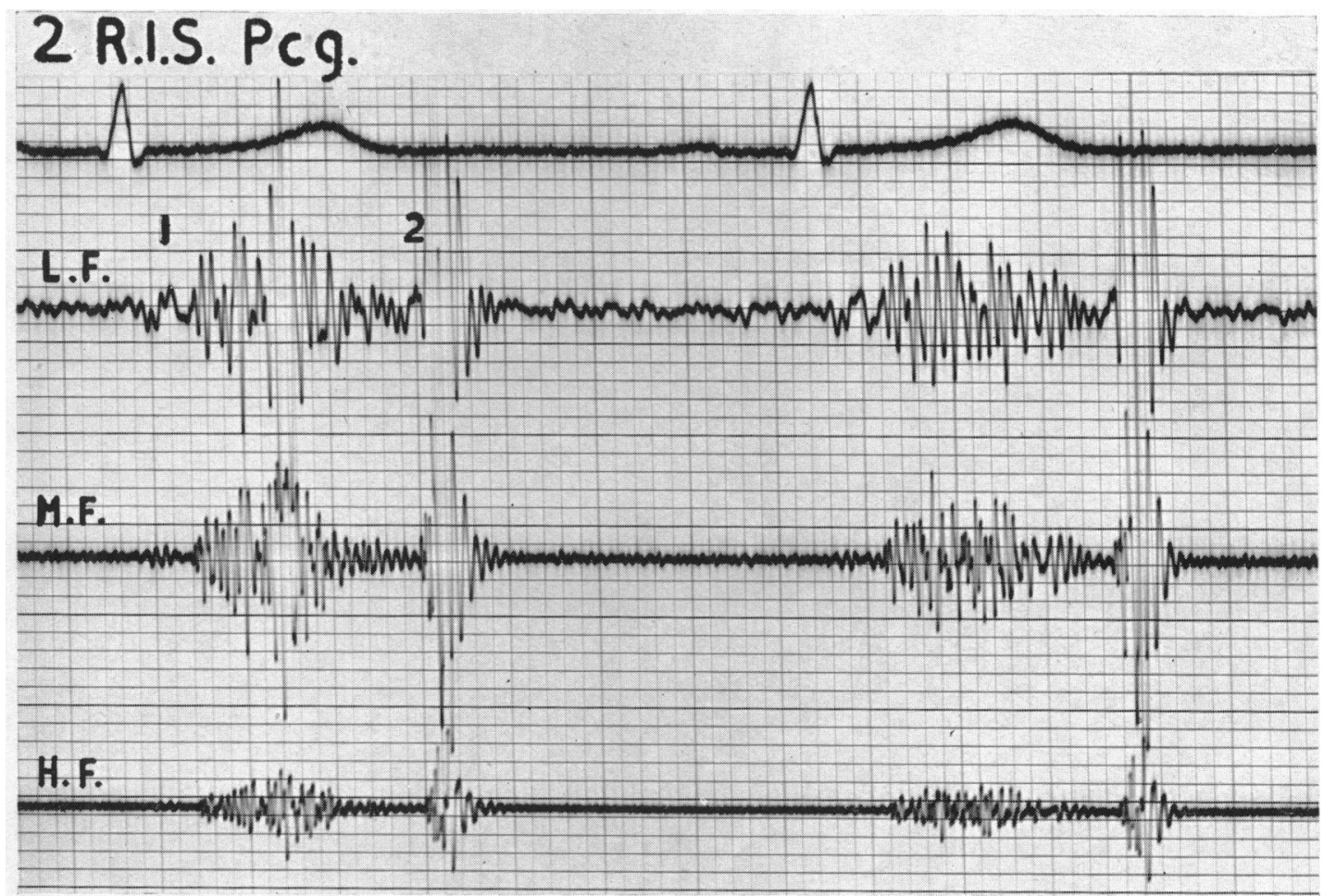

FIG. 6.-Phonocardiogram from the second right intercostal space in a case of congenital aortic stenosis, showing high amplitude of aortic second sound (2).

\section{The Arterial Pulse}

The carotid arterial pulse, recorded from the suprasternal notch, was studied in ten patients; in one there was aortic incompetence as well as stenosis. An anacrotic notch was present, onethird to half-way up the ascending limb of the pulse wave in eight instances (Fig. 7); in six it was well marked and in two it was present as a slight inflection of the upstroke of the pulse. The maximum height of systolic ejection was reached at about mid-systole in the majority of cases. The major portion of systole was occupied in the pulse tracing by low-frequency vibrations originating from the systolic murmur and giving a cock's comb appearance to the pulse wave. These vibrations have been called carotid shudder (Evans and Lewes, 1945), and they were present in all ten patients. The dicrotic notch was well marked in nine patients, and was absent in the one who also showed evidence of aortic incompetence. 


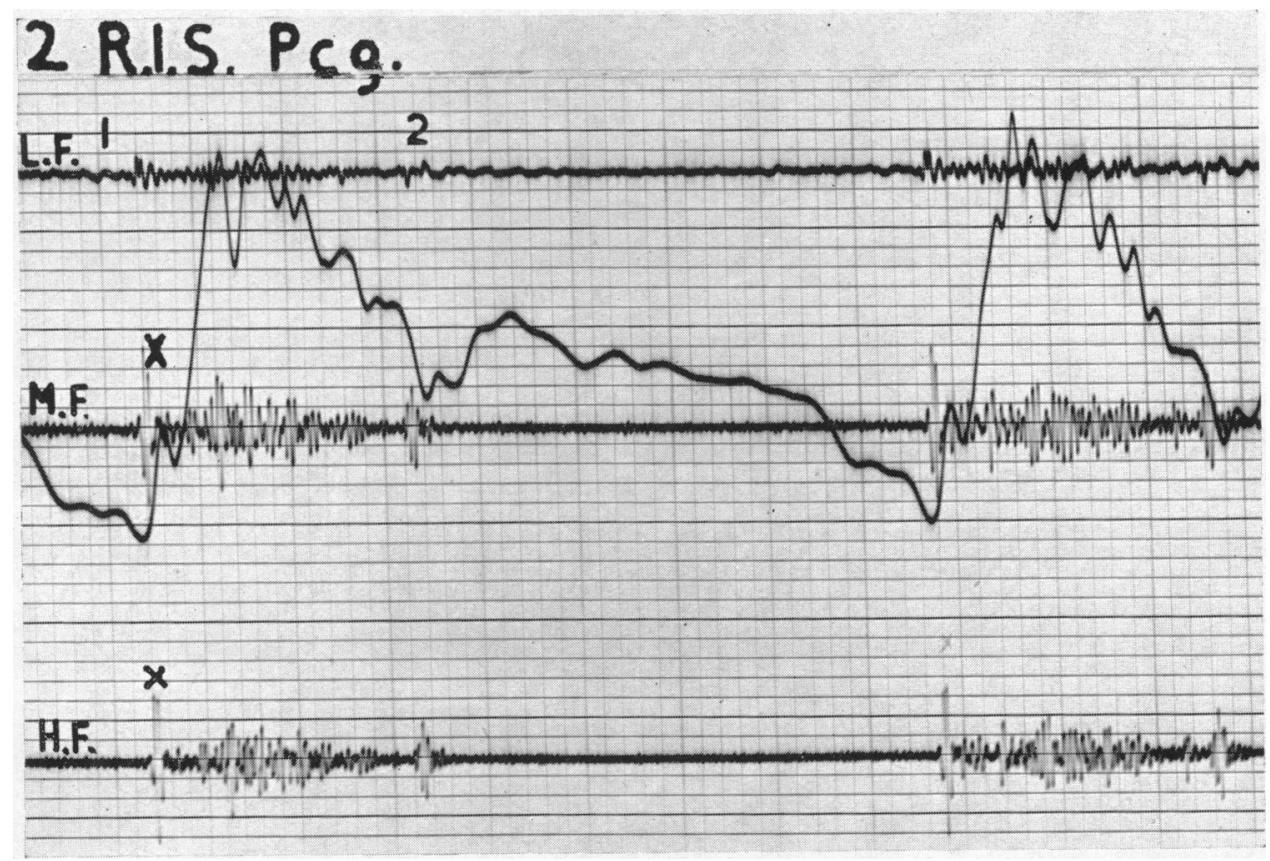

FIG. 7.-Phonocardiogram from the second right intercostal space in a case of congenital aortic stenosis showing the character of the carotid pulse. In this case the aortic second sound was of low amplitude.

\section{Discussion}

On auscultation, we have been impressed by the common occurrence of what appears to be an accentuated first heart sound at the apex in cases of congenital aortic stenosis. Moreover, in some patients it is possible to detect wide splitting of the first sound, and in these the accentuation is of the second component. This can be distinguished from the narrow splitting of the first sound at the apex (0.02-0.03 sec.) heard in normal subjects (Leatham, 1954). Analysis of these sounds in aortic stenosis by phonocardiography has shown two distinct components in most cases, separated by an average of $0.05 \mathrm{sec}$. The first component appears to coincide with the moment of mitral valve closure and is of rather high amplitude in some cases. The second component does not appear to be part of the first heart sound, as it occurs after the onset of aortic systolic ejection. It is believed to be an aortic systolic ejection sound; and does not appear to be directly related to opening of the aortic valve as has been suggested previously (Wolferth and Margolies, 1945; Reinhold and Nadas, 1954). A similar sound has been described in cases of systemic hypertension, aortic stenosis and incompetence (Lian et al., 1941; Leatham and Vogelpoel, 1954) and aortic aneurysm (Wolferth and Margolies, 1945). It seems to be analogous to the early systolic sound heard with dilatation of the pulmonary artery (Lian and Welti, 1937; Leatham and Vogelpoel, 1954), and is distinguishable from this by the fact that it is best heard at the apex.

It has been stated that the aortic second sound is normal in subaortic stenosis and diminished in valvular aortic stenosis (Brown, 1950; Wood, 1950; Brofman and Feil, 1952). Grishman et al. (1947), however, did not find that variations in intensity of the sound were of value in differentiating between these two types of stenosis and they were the first to emphasize that accentuation of the second sound was occasionally present in this disease. Lewes (1951) has also described one case of aortic valvular stenosis, proved at autopsy, with an accentuated aortic second sound. In our fifteen patients the aortic second sound was accentuated or normal in all but one instance. It is difficult to explain the accentuation of this sound in cases of subaortic stenosis with normal aortic 
valves unless the dilatation of the aorta allows for better transmission of sound to the surface of the chest (Wolferth and Margolies, 1945). Splitting of the second sound in the pulmonary area was not detectable in the majority of these patients and the average time interval between aortic and pulmonary valve closure was $0.02 \mathrm{sec}$. This was half the average interval in twenty-five normal subjects and this difference may be due to delay in aortic valve closure in aortic stenosis owing to slight prolongation of left ventricular systole. This would then be analogous to the delay of pulmonary valve closure in pulmonary stenosis (Leatham, 1954).

The pattern of the carotid pulse taken from the suprasternal notch is characteristic in this condition (Grisham et al., 1947; Brofman and Feil, 1952), owing to the rather marked anacrotic notch and the presence of carotid shudder.

We have not attempted to differentiate between valvular and subaortic stenosis in these children as we know of no way of doing so save at autopsy or possibly at operation. If it is true that a normal aortic second sound and a well marked dicrotic notch on the arterial pulse tracing indicate subaortic stenosis (Brofman and Feil, 1952), then fourteen out of our fifteen cases would fall into this group, but we believe that, at present, there is not sufficient evidence to enable us to make this differentiation.

\section{SUMMARY}

A loud early aortic systolic ejection sound was heard and recorded at the apex in fifteen patients with congenital aortic stenosis. In six patients there was an impression of wide splitting of the first heart sound at the apex due to the aortic systolic sound following the mitral valve closure component of the first sound after an interval of $0.05 \mathrm{sec}$.

The second heart sound in the aortic area appeared to be normal or accentuated in all but one patient; and the interval separating the aortic and pulmonary components of the second sound in the pulmonary area was less than normal, giving the impression of a single second sound on auscultation in many instances.

The arterial pulse recorded from the suprasternal notch showed an anacrotic notch in the majority of patients and coarse vibrations synchronous with the systolic murmur in every case.

We would like to thank Dr. Aubrey Leatham for his helpful criticism of this work, and Mr. G. H. Bryant for his technical advice and assistance.

\section{REFERENCES}

Abbott, M.E. (1936). Atlas of Congenital Cardiac Disease. New York.

Bazett, H. C., Cotton, F. S., Laplace, L. B., and Scott, J. C. (1935). Amer. J. Physiol, $113,312$.

Brofman, B. L., and Feil, H. (1952). Circulation, 6, 817.

Brown, J. W. (1950). Congenital Heart Disease. Staples, London.

Campbell, M., and Kauntze, R. (1953). Brit. Heart J., 16, 179.

Dock, W. (1933). Arch. intern. Med., 51, 737.

Evans, W., and Lewes, D. (1945). Brit. Heart J., 7, 171.

Grishman, A., Steinberger, M. F., and Sussman, M. C. (1947). Med. Clin. N. Amer., $31,543$.

Leatham, A. (1951). Brit. Heart J., 13, 153.

(1954). Lancet, 2, 607.

- and Vogelpoel, L. (1954). Brit. Heart J., 16, 21

Lewes, D. (1951). Brit. med. J., 1, 211.

Lian, C., and Welti, J. J. (1937). Arch. Mal. Coeur., 30, 947.

-, Minot, G., and Welti, J. J. (1941). Phonocardiographie. Masson, Paris.

Luisada, A. A., Fleischner, F. G., and Rappaport, M. B. (1948). Amer. Heart J., 35, 348.

Rappaport, M. B., and Sprague, H. B. (1942). Amer. Heart J., 23, 591.

Reinhold, J. D. L., and Nadas, A. S. (1954). Amer. Heart J., 47, 405.

Wolferth, C. C., and Margolies, A. (1945). Stroud's Diagnosis and Treatment of Cardiovascular Disease. F. A. Davis \& Co., Philadelphia.

Wood, P. (1950). Diseases of the Heart and Circulation. Eyre and Spottiswoode, London.

Young, D. (1944). Amer. Heart J., 28, 440. 